\title{
Prevalence of female sexual dysfunction in Damietta governorate
}

\author{
Hassan Abou Khodair ${ }^{1}$, Hany Othman Abo Al-Wafa ${ }^{1}$, Salwa Mohamed Mostafa Rotab ${ }^{2}$ \\ ${ }^{1}$ Dermatology, Venereology and Andrology Department, Faculty of Medicine, Al-Azhar University, \\ Damietta, Egypt, ${ }^{2}$ Dermatology Hospital, Damietta, Egypt
}

Corresponding Author: Salwa Mohamed Mostafa Rotab, Mobile: 01000690887, E Mail: msalwa788@ gmail.com

\begin{abstract}
Aim: to assess the prevalence of female sexual dysfunction among women of Damietta governorate Patients and methods: 500 randomly selected sexually active non-pregnant married women at age 18 - 45 years from outpatient clinics of Al-Azhar University Hospital were subjected to filling out the Arabic validated FSFI.

Results: The frequency of female sexual dysfunction among women of Damietta Governorate was $62 \%$ of participants. There was a statistically significant difference between women with female sexual dysfunction (FSD) and women without FSD in age, age of marriage and education level ( $\mathrm{P}<.0001)$. Also, women not working were at higher risk to get FSD $(\mathrm{P}<.001)$ with the significant impact of socioeconomic level on having FSD.

Also, we reported a statistically significant difference between women with FSD and women without FSD in the mode of delivery and women used IUD \& $72.6 \%$ had a history of circumcision. There was a statistically significant difference between women with FSD vs women without in mean score of desire, arousal, lubrication, orgasm, satisfaction, and pain as women with FSD showed less score in all domains compared to women without the disease.

Conclusion: FSD was a significant health problem in Damietta that needs to be investigated more deeply and assessing associated risk factors. Low rate of overt complaints regarding sexual problems among Egyptian women does not indicate lack of sexual interest but reflects cultural factors such as shyness, embarrassment, reluctances of the women and lack of physicians' awareness which lead to inadequate identification and management of such problems.
\end{abstract}

Keywords: Circumcision, Damietta Governorate, Sexuality, Sexual Dysfunction

\section{Introduction}

Human sexuality is a process that involves the integration of different organ systems and requires neurologic, vascular and endocrine coordination ${ }^{(1)}$.

Female sexual functioning is a state of ability to achieve sexual arousal, lubrication, orgasm, and satisfaction and results in wellbeing and state of wellness, with good quality of life ${ }^{(2)}$.

Female sexual dysfunction (FSD) is defined as a disorder of sexual desire, arousal, orgasm, and sexual pain that lead to personal distress or interpersonal difficulties. It is a multifactorial, age-related, progressive problem (3).

Several factors have been found to affect FSD. These include anatomical, physiological, medical, psychological and social factors ${ }^{(4)}$.

Epidemiological data on sexual dysfunction are relatively scanty and vary widely (3). In analysis of data in United States (US) from the national health and social life survey; it was found that sexual dysfunction is more prevalent in women $(43 \%)$ than in men $(31 \%)^{(5)}$.

An analysis of collected data in Egypt revealed a high prevalence of FSD (52\%) with sexual desire disorders as the commonest type of sexual dysfunction. The prevalence of desire, orgasm, arousal, pain, and sexual satisfaction disorders were $(35 \%),(29 \%),(21 \%),(20 \%)$, $(15 \%)$ respectively ${ }^{(2)}$.

This study aimed to assess the prevalence of female sexual dysfunction among women of Damietta Governorate.

\section{Patients and Methods}

This study included 500 randomly selected non-pregnant married women at sexually active age ( 18 - 45 years old) from outpatient clinics of Al-Azhar University Hospital. Informed consent was taken from every patient. The study was approved by the Ethics Board of Al-Azhar University.

Female in the childbearing period, female married with the regular marital relationship, and can read and understand the 
Arabic language without any difficulties were included in this study.

Female had chronic illness that affects sexual performance (cardiovascular disease, diabetes mellitus, neurologic disease, hypertension, renal failure, etc...), used medications that affect sexual performance (antidepressant, antihypertensive, etc....), presence of sexual dysfunction in male partner (erectile dysfunction, premature ejaculation etc...) and pregnant and lactating women were excluded from the study.

All females were subjected to filling out the Arabic validated FSFI that was developed by Rosen et al., which is a 19-item, self-report measure of sexual dysfunction in women ${ }^{(6)}$.

\section{Statistical analysis}

Sample Size Calculation: Using One Proportion Power Analysis in NCSS\& PASS program, a minimum sample size to assess the prevalence of female sexual dysfunction among women of Damietta governorate is 500 women to detect a difference of 0.1 and achieve $80 \%$ power with a target significance level at $5 \%$.

The clinical data were recorded on a report form. These data were tabulated and analyzed using the computer program SPSS (Statistical package for social science) version 20. Two types of statistics were done:

Descriptive statistics were calculated for the data in the form of frequency and distribution for qualitative data. In the statistical comparison between the different groups, the significance of difference was tested using one of the following tests: Inter-group comparison of categorical data was performed by using chi square test $\left(X^{2}\right.$-value) and fisher exact test (FET).

\section{Results}

This study included 500 randomly selected non-pregnant married women at sexually active age (18 - 45 years old) from outpatient clinics of Al-Azhar University Hospital. Mean age of these participants was $(32.95 \pm 7.1$ years), the majorities $(42.4 \%)$ of participants were between (30-39) years, $(35.8 \%)$ were between (21-29) years while $20.6 \%$ were from 39-49 years age group and $1.2 \%$ were less than 20 years old. According to education level, the level of the majority was moderate $(46.8 \%)$ followed by $(33.6 \%)$ with high-level education, and the least was low- level education (19.6\%). As for socioeconomic level; the level of the majority was moderate (59\%) followed by (32.6\%) with high socioeconomic level, and the least was low level $(8.4 \%)$. While according to work status $(51.2 \%)$ of women were working while the rest (48.8\%) were not.

Mean age of husbands was (37.44 \pm 7.8 years), the majority $(42.4 \%)$ of husbands was between (30-39) years, (53.8\%) were between (21-29) years while $20.6 \%$ were from $39-49$ years age group and $1.2 \%$ were less than 20 years old. While $(50.6 \%)$ were smokers and $49.4 \%$ were not. The majority of them were of moderate-level education (46.8\%) followed by (33.6\%) with high-level education, and the least with low-level education (19.6\%).

The mean age of marriage of participants (23.98 \pm 3.5 years) ranged from 18 years to 35 years, while mean duration of marriage was $(8.97 \pm 5.8$ years $)$ and ranged from 1 year to 23 years. According to the mode of the delivery; majority of women delivered by CS $(69.4 \%)$ followed by (24\%) of participants delivered normally while (6.6\%) didn't deliver before. The majority of women used IUD $(60 \%)$ followed by $(26 \%)$ used OCPs while (10.4\%) used nothing. 55.2\% of women had a positive history of circumcision versus (44.8\%) were not circumcised.

The frequency of female sexual dysfunction among women of Damietta governorate constituted $62 \%$ of participants (Figure 1).

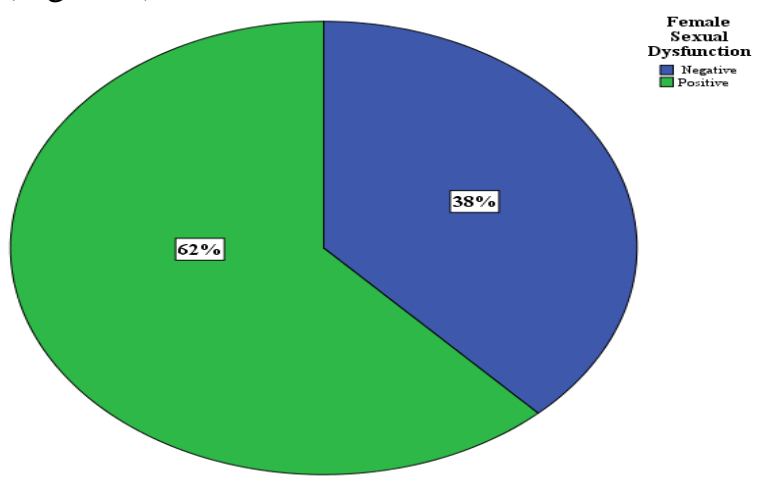

Figure 1: Prevalence of female sexual dysfunction among women of Damietta governorate

Assessment of FSFI shows that the lowest mean score was reported for orgasm score (3.5) and desire score (3.59) while the highest score for satisfaction score (4.5) and lubrication score (4.24) (Table 1).

Table1: Female sexual function index (total and domain scores). 


\begin{tabular}{|l|l|l|l|l|l|l|l|}
\hline $\begin{array}{l}\text { 焉 } \\
\text { Mean } \pm \text { SD }\end{array}$ & $\begin{array}{l}\text { Arousal } \\
\text { score }\end{array}$ & $\begin{array}{l}\text { Lubrication } \\
\text { score }\end{array}$ & $\begin{array}{l}\text { Orgasm } \\
\text { score }\end{array}$ & $\begin{array}{l}\text { Satisfaction } \\
\text { score }\end{array}$ & $\begin{array}{l}\text { Pain } \\
\text { score }\end{array}$ & $\begin{array}{l}\text { Total } \\
\text { score }\end{array}$ \\
\hline score & 4.26 & $4.1 \pm .89$ & $4.24 \pm .99$ & $3.5 \pm 1.2$ & $4.5 \pm 1.14$ & $3.9 \pm 1.1$ & $\begin{array}{l}23.8 \pm \\
4.8\end{array}$ \\
\hline
\end{tabular}

There was a statistically significant difference between women with FSD and women without FSD according to age groups as group (30-39) had higher risk to have FSD (52.9\%) compared to $25.3 \%$ in women without FSD $(\mathrm{P}<.0001)$, and according to education level, women with moderate education level recorded the highest percentage in having FSD $(52.6 \%)$ compared to (47.4\%) women free from disease. Also, women not working were at higher risk to get FSD compared to working women $(\mathrm{P}<.001)$. Lastly, there was a significant impact of socioeconomic level on having FSD as a high level was the least affected category (7.1\%) compared to low and moderate level $(41.3 \%$ vs $51.6 \%)$ respectively.

There was a statistically significant difference between the 2 groups according to the age of marriage and duration as positive FSD showed the larger mean of age and duration of marriage compared to the negative group $(\mathrm{P}<.001)$ (Table 2).

Table 2: Comparison between women with FSD vs women without FSD according marital status history

\begin{tabular}{|l|c|c|c|}
\hline & $\begin{array}{l}\text { Positive FSD } \\
(\mathbf{N}=310)\end{array}$ & $\begin{array}{l}\text { Negative FSD } \\
(\mathbf{N}=\mathbf{1 9 0})\end{array}$ & P value \\
\hline Age of marriage (years) & & & \\
\hline Mean \pm SD & $25.1 \pm 3.5$ & $22.23 \pm 2.8$ & $\mathrm{P}<.001^{*}$ \\
\hline Duration of marriage (years) & & & $\mathrm{P}<.001^{*}$ \\
\hline Mean \pm SD & $10.7 \pm 5.4$ & $6.2 \pm 5.3$ & \\
\hline
\end{tabular}

*denotes significance, FSD: female sexual dysfunction

Also, we reported a statistically significant difference between women with FSD and women without FSD in the mode of delivery: women who labored normally were at higher risk to get FSD than other mode of delivery (72.3\%). Women used IUD showed higher percentage to get FSD than other methods $(66.5 \%)$. Lastly women with a history of circumcision were more likely to have FSD (72.6\%).

There was a statistically significant difference between women with FSD vs women without FSD according to mean score of desire, arousal, lubrication, orgasm, satisfaction, and pain as women with FSD showed fewer score in all domains compared to women without the disease (Table 3).

Table 3: Comparison between women with FSD vs women without FSD according Female sexual problems

\begin{tabular}{|c|c|c|c|}
\hline & $\begin{array}{c}\text { Positive } \\
\text { FSD } \\
(\mathbf{N}=310) \\
\end{array}$ & $\begin{array}{c}\text { Negative } \\
\text { FSD } \\
(\mathbf{N}=190)\end{array}$ & $\begin{array}{c}\text { Test of significance } \\
\text { (p) }\end{array}$ \\
\hline \multicolumn{4}{|l|}{ Desire score } \\
\hline Mean \pm SD & $2.9 \pm 1.03$ & $4.7 \pm .68$ & $\mathrm{P}<.001 *$ \\
\hline \multicolumn{4}{|c|}{ Arousal score } \\
\hline Mean \pm SD & $3.6 \pm .68$ & $4.8 \pm .64$ & $\mathrm{P}<.001 *$ \\
\hline \multicolumn{4}{|c|}{ Lubrication score } \\
\hline Mean \pm SD & $3.7 \pm .83$ & $5 \pm .6$ & $\mathrm{P}<.001 *$ \\
\hline \multicolumn{4}{|c|}{ Orgasm score } \\
\hline Mean \pm SD & $2.9 \pm 1$ & $4.5 \pm .7$ & $(\mathrm{P}<.001 *$ \\
\hline \multicolumn{4}{|c|}{ Satisfaction score } \\
\hline Mean \pm SD & $4 \pm 1$ & $5.4 \pm .7$ & $\mathrm{P}<.001 *$ \\
\hline \multicolumn{4}{|l|}{ Pain score } \\
\hline Mean \pm SD & $3.5 \pm .97$ & $4.5 \pm .9$ & $\mathrm{P}<.001 *$ \\
\hline
\end{tabular}

*denotes significance, FSD: female sexual dysfunction

\section{Discussion}


Sexuality is an important part of health, quality of life and general wellbeing. Sexual dysfunction is characterized by disturbance in sexual desire and psychophysiological changes associated with the sexual response cycle in men and women. (7) Sexual dysfunction adversely affects the quality of life and may often be responsible for psychopathological disturbances, and yet it remains a taboo subject in many countries ${ }^{(8)}$.

For women, many factors can affect sexual functioning including age, fertility status, hormonal levels, socioeconomic factors, quality of life, educational level, relationship with spouse, sexual knowledge and behaviors, family planning methods, and physical and mental health ${ }^{(9)}$.

Sexual dysfunction was more prevalent in women than in men and was associated with various demographic characteristics, including age and educational attainment ${ }^{(10)}$. In our study, among 500 selected women, the mean age was $(32.95 \pm 7.1$ years), majority $(42.4 \%)$ of participants were between (30-39) years, (35,8\%) were between (21-29) years while $20.6 \%$ were from 39-49 years age group and $1.2 \%$ was less than 20 years old.

Similarly, a cross-sectional clinic-/hospitalbased survey to assess the prevalence and associated factors of female sexual dysfunction (FSD) in Lower Egypt was conducted by Elnashar et al. revealed that most participants were in the age groups 20 to 29 years and 30 to 39 years (48.9\% and $30.9 \%$, respectively) ${ }^{(3)}$.

Also, a total of 648 patients from the outpatient clinic of Sohag University Hospital were recruited to participate in the Hassanin et al. study, most of the patients were in the age groups 30-39 years and 40-50 years (36.8\% and $25.0 \%$, respectively) ${ }^{(10)}$ and in Ibrahim et al. study, the studied females were in the age group 20-59 with mean age 39.5 years old ${ }^{(2)}$.

According to education level majority of our patients had a moderate level $(46.8 \%)$ followed by (33.6\%) with high-level education, and the least had low-level education (19.6\%).

Many of the participants in Elnashar et al. study $(28.6 \%)$ were illiterate and $48 \%$ had a secondary level of education (3), but in Hassanin et al. study, most of the participants had an education level below university level $(55.6 \%)^{(10)}$ and in Ibrahim et al. study, most of the studied females $(39.5 \%)$ had a primary educational level ${ }^{(2)}$.
As for socioeconomic level, $59 \%$ of our patients had a moderate level followed by $32.6 \%$ with high socioeconomic level, and the least was low level $(8.4 \%)$ while according to work status, (51.2\%) of women were working but the majority of respondents in Elnashar et al. study, were housewives $(70.4 \%)$, with only $1.3 \%$ owning property, and among their spouses, $55.6 \%$ had private work, $21.2 \%$ had a government job and only $4.8 \%$ had their own property ${ }^{(3)}$.

While in Lou et al. study, of the participants, 2069 (44.0\%) engaged in intellectual occupations, 719 (15.3\%) engaged in physical work, $1528(32.5 \%)$ engaged in work that was both physical and intellectual, and 381 (8.1\%) were homemakers ${ }^{(11)}$ and this is in agreement with our finding.

The mean age of marriage of our participants was $(23.98 \pm 3.5$ years $)$ with a range from 18 years to 35 years, with a mean duration of marriage $(8.97 \pm 5.8$ years $)$ and the range from 1 year to 23 years. In agreement with us, FSD was assessed with a detailed 19-item female sexual function index (FSFI) questionnaire among 153 fertile females in Mishra et al. study. They found the mean duration of marriage was $11.23 \pm 8.39$ years and it was also observed that FSD was more prevalent in females with duration of marriage $>16$ years ${ }^{(12)}$. According to the mode of delivery, we found the majority of women delivered by CS (69.4\%) followed by (24\%) of participants delivered normally while $(6.6 \%)$ have not delivered yet. The majority of women used IUD (60\%) followed by (26\%) used OCPs while (10.4\%) used nothing while (3.6\%) used another method. Ibrahim et al. study has a different result as they found that vaginal delivery was the mode of delivery in $63.9 \%$ of the females while $16.3 \%$ were subjected to CS. The most common contraceptive method was IUCD $(40.5 \%)$ while $9.8 \%$ did not use any method of contraception which was similar to our results ${ }^{(2)}$.

Female circumcision was one of the traditional practices that were still performed in Egypt and was a possible cause of female sexual dysfunction (FSD). Circumcision status (now called female genital mutilation according to the World Health Organization's latest recommendations) was associated with an elevated risk of experiencing sexual problems (13) $55.2 \%$ of our participants had a positive history of circumcision. The study by $\boldsymbol{E} \boldsymbol{l}$ - 
Defrawi et al. suggested that circumcision has a negative impact on a woman's psychosexual life by raising common problems such as vaginal dryness during intercourse, lack of sexual desire, less pleasure, less orgasm and having difficulty to reach orgasm (14). Approximately $90 \%$ of women in Elnashar et al. study was circumcised; therefore, this was a significant cause of sexual problems ${ }^{(3)}$.

This corroborates the report of EL-Nashar et al. who found, in their sample of 264 women in Benha City, that circumcised women $(75.8 \%)$ were more likely to have marital problems such as loss of sexual desire, dyspareunia, and lower satisfaction rate, in addition to psychological problems, mainly anxiety, depression and hostility ${ }^{(15)}$.

Assessment of Female sexual function index (FSFI) showed that the lowest mean score was reported for orgasm score $(3.5 \pm 1.2)$ and desire score $(3.59 \pm 1.26)$ while the highest score for satisfaction score was $(4.5 \pm 1.14)$ and lubrication score $(4.24 \pm .99)$. In the current study, many participants explained their lower sexual desire to be because of circumcision and socioeconomic circumstances such as economic stressors and increased household duties. This was also noted by Shokrollahi et al. who found too little foreplay before sexual intercourse to be the most common sexual difficulty among their sample of women ${ }^{(16)}$. In agreement with us, a total of $365(60.7 \%)$ women in Hassanin et al., study, reported having difficulties with orgasm; low sexual arousal was reported by 341 women $(56.7 \%)$; lack of lubrication was reported by 317 (52.8\%) women; sexual dissatisfaction was reported by 322 (53.6\%) women; low sexual desire was reported by 399 (66.4\%) women; and sexual pain (dyspareunia) was reported by 385 $(64.1 \%)$ women ${ }^{(10)}$.

There was clearly a need for more longitudinal studies for all of the dysfunctions in order to obtain more accurate incidence data. There was reasonably valid descriptive epidemiological data indicating that about $40-45 \%$ of adult women have at least one manifest sexual dysfunction ${ }^{(17)}$. The frequency of female sexual dysfunction among women of Damietta governorate constituted $62 \%$ from participants. The Elnashar et al. study presents epidemiological data on the prevalence and predictors of FSD in Lower Egypt, represented by a sample taken from the Dakahlia Governorate. It emphasizes the high prevalence
(68.9\%) of sexual difficulties among the women studied ${ }^{(3)}$.

Ibrahim et al., found that 269 women (52.8\% of the participants) had sexual dysfunction in Suez Canal district in Egypt ${ }^{(2)}$. Hassanin et al. study presented epidemiological data on the prevalence and associated factors of FSD in Upper Egypt; it emphasizes the high prevalence (76.9\%) sexual dysfunction among the women studied and the importance of direct questioning about sexual function in gynecology and family planning clinics. The low rate of direct complaints about sexual problems among women in Upper Egypt probably reflects cultural factors, such as shyness and embarrassment. In addition, lack of awareness of FSD by physicians can lead to inadequate identification and management of these problems ${ }^{(10)}$.

Women's education and socioeconomic status do play a role in their outlook toward sexual life. As regard to education level, we found a statistically significant difference between women with FSD and women without FSD $(\mathrm{P}<0.0001)$ as the highest percentage of women with FSD (52.6\%) had moderate education level. The higher incidence of sexual dysfunction in better educated individuals was surprising given that they were healthier and have lifestyles that were less physically stressful and emotionally demanding. However, a higher educational level may also be associated with an increase in the women's ability to freely express their dissatisfaction ${ }^{(3)}$. This finding agrees with those of Fajewonyomi et al. they found that FSD was more prevalent in women with higher education $(43.4 \%)$ as compared to women with no formal education $(7.3 \%)^{(19)}$.

Ibrahim et al. showed that females with FSD were most of them circumcised $(88.1 \%)$ and found non-significant higher incidence of FSD among highly educated females. This higher incidence of sexual dysfunction in better educated individuals were surprising given that they are healthier and have lifestyles that are less physically stressful and emotionally demanding. However, a higher educational level may also be associated with an increase in the women's ability freely to express their dissatisfaction ${ }^{(2)}$.

Also, women not working were at high risk to get FSD compared to working women $(\mathrm{P}<0.001)$ and there was a significant impact of socioeconomic level on incidence of FSD as 
those with high level were the less exposed category $(7.1 \%)$ compared to low and moderate levels $(41.3 \%$ vs $51.6 \%)$ respectively $(\mathrm{P}<0.0001)$. In Egypt, the lack of correlation may be because of a lack of a large difference in the economic situation of the studied groups. This finding contradicts that of Laumann et al. who found a positive correlation between deterioration in economic position and sexual dysfunction ${ }^{(20)}$.

In contrary, in Elnashar et al. study, work status and source of income had no impact upon sexual function greatly, although in $28.1 \%$ of respondents, unfavorable economic circumstances were among the aggravating factors for their sexual problems ${ }^{(3)}$.

In this study, there was a statistically significant difference $(\mathrm{P}<0.001)$ between the two groups according to age of marriage and duration, as those with positive FSD had older age at the time of marriage and longer duration compared to negative group. In Hassanin et al. study, patients with FSD were significantly more likely to be older than 40 years $\left(\chi^{2}=10.4\right.$, $\mathrm{P}=0.004)$, were married for 10 years or more $\left(\chi^{2}=12.71, \mathrm{P}=0.026\right)$ and were married to a man aged 40 years or older $\left(\chi^{2}=13.64, \mathrm{P}=0.021\right)$ but they failed to achieve statistical significance ${ }^{(10)}$ and Tehrani et al. found a statistically significant relationship between sexual dysfunction and duration of marital life ${ }^{(8)}$.

In the Jafarzadeh et al. study, a significant correlation was observed between duration of relationship with partner and prevalence of FSD (21). Another research performed in the same region as the previous study indicated that the rate of sexual problems decreased significantly with longer duration of relationship between partners ${ }^{(22)}$. These inconsistencies between the findings could be due to the use of different questionnaires. While first study used researcher-designed questionnaires, the second used the validated Persian translation of FSFI scale.

Also, among our cases, there was a statistically significant difference between women with FSD and women without FSD in either mode of delivery as normal labor increased the risk (72.3\%) for FSD than CS or in methods of contraception (women used IUD showed higher percentage $(66.5 \%)$ to get FSD than other methods) or in history of circumcision as circumcised women were more likely to have FSD (72.6\%). In Hassanin et al. study, there was no significant difference between women with FSD and women without FSD regarding use of contraception $\left(\chi^{2}=2.25, \mathrm{P}=0.065\right)^{(10)}$.

According to Elnashar et al. study mode of delivery and type of contraception used were not statistically significantly associated with sexual dysfunction, but they reported that circumcision status significantly correlated with the extent of sexual problems ${ }^{(3)}$. Also, $\boldsymbol{E l}$ Naser et al. study showed that scores of sexual desire, arousal, orgasm, satisfaction and pain were comparable between circumcised and uncircumcised groups, while lubrication score was significantly higher in the uncircumcised group. The total FSFI score demonstrated nonsignificant difference between the circumcised group compared to the uncircumcised one ${ }^{(23)}$.

We found a statistically significant difference in mean score of desire, arousal, lubrication, orgasm, satisfaction and pain; between women with FSD vs women without FSD ( $\mathrm{P}<0.001$ for all) as women with FSD showed less score in all domains compared with women without FSD. A community-based cross-sectional descriptive study was carried out by Tehrani et al. on 784 married women living in urban areas of 4 province of Iran. Their results demonstrated $27.3 \%$ prevalence of sexual dysfunction. Among women with sexual dysfunction, the frequency of desire, arousal, lubrication, and orgasmic disorders were $35.6 \%, 39.9 \%, 18.9 \%$ and $27.3 \%$ respectively (8).

In Mishra et al. study, the mean score of FSD and various domains of FSD were calculated in both groups of patients, those with FSD and those without FSD and there was insignificant difference in all domains $(\mathrm{P}<0.01)^{(12)}$.

The results of the present study should be interpreted with recognition of its limitations. First, the study group consisted of women who attended an outpatient clinic, which may not be representative of the community. Communitybased sampling may not be possible because of the sensitivity of the topic. Second, the study included married women and excluded unmarried women (because of cultural barriers) and women who were separated or divorced (because of the similar cultural barriers that prohibit a woman who was supposedly sexually inactive to talk about sexuality). Women who were separated or divorced may be more at risk of FSD, which may have falsely raised the prevalence of FSD if they were included. Although FSD is highly prevalent; it was still a silent problem. Third, cultural factors such as 
shyness and embarrassment of women and lack of awareness and training of physicians leads to inadequate identification and management of these problems. This emphasizes the importance of direct questioning about sexual functioning as part of the routine checklists undertaken in gynecology and family planning clinics. FSD needs to be recognized as a significant public health problem in Egypt, with an urgent need for further research, particularly studies into awareness and competency of physicians in the management of FSD.

In conclusion, FSD was a significant health problem in Damietta that needs to be investigated more deeply and assessing associated factors and so community-based studies are recommended. The generally low rate of overt complaints regarding sexual problems among Egyptian women does not indicate lack of sexual interest but rather reflects cultural factors such as shyness, embarrassment and reluctances of the women and lack of physicians' awareness and training, which lead to inadequate identification and management of such problems. This result emphasizes the high prevalence of sexual problems even among apparently healthy individuals and also emphasizes the importance of direct questioning about sexual function as part of the routine checklist in gynecology and family planning clinics.

\section{References}

1.Drench ME, Losee RH(1996): Sexuality and sexual capacities of elderly people. Rehabilitation Nursing ,21:118-123

2.Ibrahim ZM, Ahmed MR, Ahmed W(2013): Prevalence and risk factors for female sexual dysfunction among egyptian women. Archives of gynecology and obstetrics ,287:1173-1180

3.Elnashar A, El-Dien Ibrahim M, ElDesoky M, Ali O, El-Sayd Mohamed Hassan M(2007): Female sexual dysfunction in lower egypt. BJOG: An International Journal of Obstetrics \& Gynaecology ,114:201-206

4.Basson R, Berman J, Burnett A, Derogatis L, Ferguson D, Fourcroy $\mathrm{J}$ et al.(2000): Report of the international consensus development conference on female sexual dysfunction: Definitions and classifications. The Journal of urology ,163:888-893
5.Addis IB, Van Den Eeden SK, WasselFyr CL, Vittinghoff E, Brown JS, Thom DH et al.(2006): Sexual activity and function in middle-aged and older women. Obstetrics and gynecology ,107:755-764

6. Rosen CB, Heiman S, Leiblum C, Meston R, Shabsigh D, Ferguson R, D'Agostino R (2000): The female sexual function index (fsfi): A multidimensional self-report instrument for the assessment of female sexual function. Journal of Sex \&Marital Therapy ,26:191-208

7.Kasif T, Band-Winterstein T(2017): Older widows' perspectives on sexuality: A life course perspective. Journal of Aging Studies ,41:1-9

8.Tehrani FR, Farahmand M, Simbar M, Afzali HM(2014): Factors associated with sexual dysfunction; a population based study in iranian reproductive age women. Archives of Iranian medicine ,17:679-684

9.McCool ME, Zuelke A, Theurich MA, Knuettel H, Ricci C, Apfelbacher C(2016): Prevalence of female sexual dysfunction among premenopausal women: A systematic review and meta-analysis of observational studies. Sexual medicine reviews ,4:197-212

10.Hassanin I, Helmy YA, Fathalla MM, Shahin AY(2010): Prevalence and characteristics of female sexual dysfunction in a sample of women from upper egypt. International Journal of Gynecology \& Obstetrics ,108:219-223

11.Lou W-J, Chen B, Zhu L, Han S-M, Xu T, Lang J-H et al.(2017): Prevalence and factors associated with female sexual dysfunction in beijing, china. Chinese medical journal ,130:1389-1394

12.Mishra VV, Nanda S, Vyas B, Aggarwal R, Choudhary S, Saini SR (2016): Prevalence of female sexual dysfunction among indian fertile females. Journal of midlife health , 7:154-158

13.apps.who.int/iris/handle/10665/63602

14.El-Defrawi MH, Lotfy G, Dandash KF, Refaat AH, Eyada M(2001): Female genital mutilation and its psychosexual impact. Journal of Sex \&Marital Therapy ,27:465-473

15.El-Nashar A(1998): Long-term impact of circumcision on health of newly married females. Zagazig University Medical Journal ,6:839-851

16.Shokrollahi P, Mirmohamadi M, Mehrabi F, Babaei G(1999): Prevalence of sexual dysfunction in women seeking services 
at family planning centers in tehran. Journal of sex \& marital therapy ,25:211-215

17.Lewis RW, Fugl-Meyer KS, Bosch R, Fugl-Meyer AR, Laumann EO, Lizza E et al. (2004): Epidemiology/risk factors of sexual dysfunction. The journal of sexual medicine ,1:35-39

18.Arnolds H(1996): Urogenital symptoms and their resulting discomfort in noninstitutionalized 50-to-75-year-old dutch women. Nederlands tijdschrift voor geneeskunde ,140:713-716

19.Fajewonyomi BA, Orji EO, Adeyemo AO(2007) Sexual dysfunction among female patients of reproductive age in a hospital setting in nigeria. Journal of health, population, and nutrition ,25:101-106
20.Laumann EO, Paik A, Rosen RC(1999): Sexual dysfunction in the united states: Prevalence and predictors. Jama. ,281:537-544 21.Jafarzadeh Esfehani R, Fazel N, Dashti S, Moshkani S, Haghighi Hasanabad F, Foji S et al.(2016): Female sexual dysfunction and its associated risk factors: An epidemiological study in the north-east of iran. Journal of Midwifery and Reproductive Health ,4:498-505 22.Bolourian Z, Ganjloo J(2007): Evaluating sexual dysfunction and some related factors in women attending sabzevar health care centers. Journal of Reproduction \& Infertility ,8:170178

23.El-Naser TA, Farouk A, El-Nashar A, Mostafa T(2011): Sexual side effects of female genital mutilation/cutting may be type dependent: A hospital-based study. J Obstet Gynecol ,1:65-74 